\title{
CONCEPÇÕES DE CORPO E A PRÁTICA PEDAGÓGICA DOS PROFESSORES DE EDUCAÇÃO FÍSICA DO ENSINO MÉDIO
}

\author{
Fernanda Azevedo Gomes da Silva \\ Universidade Federal do Rio de Janeiro, Rio de janeiro, Rio de Janeiro, Brasil. \\ Luis Aureliano Imbiriba Silva \\ Universidade Federal do Rio de Janeiro, Rio de janeiro, Rio de Janeiro, Brasil. \\ Silvia Maria Agatti Lüdorf \\ Universidade Federal do Rio de Janeiro, Rio de janeiro, Rio de Janeiro, Brasil.
}

\begin{abstract}
Resumo: O objetivo do estudo foi analisar e discutir as concepções de corpo de professores de Educação Física atuantes no ensino médio. De natureza qualitativa, a pesquisa foi realizada por meio de entrevistas com 21 professores de escolas públicas e privadas. Os dados foram tratados mediante análise de conteúdo. Detectou-se que o professor do ensino médio tem apresentado concepções de corpo variadas que coexistem de acordo com o contexto no qual está inserido. Ainda que a preocupação com a saúde venha a se constituir a principal marca na prática pedagógica neste nível de ensino, há ainda considerável preocupação com o desenvolvimento das capacidades físico-esportivas dos alunos, bem como com a abordagem de conteúdos e vivências envolvidos nas tendências renovadoras da área.
\end{abstract}

Palavras-chave: Corpo. Educação Física. Professor. Ensino Médio.

\section{Considerações Introdutórias}

O corpo auxilia na compreensão da identidade humana, pode ser considerado um dos elementos fundamentais na representação de uma dada sociedade (LE BRETON, 2011) e também sofre as influências do contexto em que está inserido (DAOLIO, 1995a; LÜDORF, 2005).

Dessa forma, os discursos envolvendo o corpo se manifestam social e culturalmente em diversas instituições (GONÇALVES e AZEVEDO, 2008) e podem, portanto, auxiliar no entendimento das representações de corpo construídas e reconstruídas também em âmbito educacional. Nesse sentido, o (re)pensar o corpo torna-se fundamental em estudos cujas reflexões envolvam as relações pedagógicas presentes na escola, mais precisamente naqueles envolvendo a Educação Física escolar.

A historiografia da área de Educação Física no Brasil apresenta de uma maneira não linear uma série de representações de corpo. De certa forma, tal diversidade acaba por moldar as noções de prática pedagógica em Educação Física que coexistem na atualidade e podem fornecer respaldo às diferentes práticas docentes. Pode-se citar, por exemplo, a aparente preocupação com a saúde, defendida de maneira significativa por documentos e leis que 
atualmente regem o ensino médio brasileiro ${ }^{26}$, tendo como característica traços higienistas, ainda presentes desde os séculos XIX e XX (GÓIS JÚNIOR e LOVISOLO, 2003).

Investigações sobre as concepções de corpo na visão dos professores de Educação Física são de suma importância pelo fato deste docente estar em uma condição privilegiada na escola, uma vez que é um dos profissionais que trabalham mais diretamente com/no/para o corpo, sobretudo no ensino médio. Sabe-se que, teoricamente, é neste momento da educação básica que os alunos estão em uma fase particular do desenvolvimento humano, na qual inúmeras transições ocorrem, afetando tanto os aspectos físicos e sexuais, quanto os aspectos cognitivos e emocionais do adolescente (ASSIS et al., 2003).

Além disso, principalmente no ensino médio, tem sido amplamente valorizada a preparação do aluno visando às exigências do vestibular (SILVA, 2002). Tal fato, dentre outros, colabora para que a própria disciplina de Educação Física, bem como as discussões sobre os objetos de estudo dos quais se apropria, como as que envolvem o corpo, sejam colocadas em segundo plano (BRASIL, 2000; BETTI, 2001; BRANDL, 2003).

Recentemente, alguns dos olhares referentes ao corpo e à Educação Física escolar no ensino médio relacionam-se à saúde em uma perspectiva de combate ao sedentarismo e à defesa da prática regular de exercícios físicos. Tenório et al. (2010), Ceschini et al. (2009) e Silva et al. (2009) investigaram, por exemplo, prevalências e fatores associados ao sedentarismo entre adolescentes. Além de observarem a elevada prevalência de inatividade física neste grupo de estudo, defenderam a necessidade iminente da prática regular de exercícios físicos para estes jovens. Assim, observa-se que a preocupação com a saúde, mesmo que sob o aspecto epidemiológico, tem sido uma temática central nos estudos ligados à Educação Física no ensino médio.

Outras publicações que envolvem a temática na Educação Física escolar neste âmbito de ensino trazem ainda investigações que podem auxiliar em uma reflexão pautada na abordagem sociocultural sobre o corpo. Darido et al. (1999), por exemplo, comentavam sobre a importância que deveria ser dada aos aspectos socioculturais na Educação Física, sobretudo no ensino médio, a fim de garantir a autonomia e reflexão do aluno quanto a cultura corporal de movimentos. Em consonância, Chicati (2000) sugeriu que as aulas de Educação Física neste nível de ensino ultrapassassem as abordagens desportivas a fim de promover a motivação dos alunos durante as aulas. Entretanto, Miranda, Lara e Rinaldi (2009) apontaram que muitos professores atuantes no ensino médio parecem não compreender bem as relações entre a Educação Física e a cultura corporal, justificando assim a pouca utilização deste conhecimento no nível médio de ensino.

Ainda que exista uma variabilidade de temas em estudos envolvendo a Educação Física e o ensino médio, observam-se ainda lacunas quanto a investigações que se proponham a buscar as relações entre as concepções de corpo dos professores e a sua prática pedagógica. Estes fatores parecem estar ligados à historiografia da área e podem auxiliar na compreensão de como a disciplina vem sendo desenvolvida no ensino médio.

Neste sentido, a presente pesquisa tem como objetivo analisar e discutir as concepções de corpo veiculadas nas relações de ensino-aprendizagem da Educação Física no ensino médio do Rio de Janeiro, sob a ótica do professor de Educação Física.

26 Os Parâmetros Curriculares Nacionais (PCN) da Educação Física no Ensino Médio, bem como as Orientações Curriculares Nacionais para o Ensino Médio, são alguns exemplos de documentos que fornecem indicações sobre os conteúdos que devem ser trabalhados no ensino médio Brasileiro. 


\section{Aspectos Metodológicos}

O presente estudo é de natureza qualitativa, se caracterizando pela análise dos significados, opiniões e representações envolvidos em determinado fenômeno (TURATO, 2003).

Dessa forma, com o intuito de conhecer a opinião de professores de Educação Física atuantes no Ensino Médio, optou-se por, primeiramente, selecionar algumas escolas da região metropolitana do estado do Rio de Janeiro. A busca por escolas de diversas localidades da região metropolitana do Estado do Rio de Janeiro ambicionava explorar as diferentes realidades sociais, econômicas e culturais dessas instituições, estratégia esta que pode propiciar a ampliação do espectro de opiniões dos sujeitos de pesquisa. Pretendeu-se ainda selecionar escolas privadas e públicas (níveis federal e estadual ${ }^{27}$ ), admitindo-se que aspectos como as relações pessoais entre professor-aluno, o perfil dos alunos, as condições salariais e trabalhistas e a "visão de mundo" do professor, poderiam ser diferentes entre as escolas.

Posteriormente, esclareceu-se a proposta da presente pesquisa e, após a assinatura da Carta de Autorização ${ }^{28}$, foi apresentado o Termo de Consentimento Livre e Esclarecido (TCLE) aos professores participantes da pesquisa, cumprindo com os preceitos éticos para pesquisas realizadas com seres humanos. A presente pesquisa está respaldada pelo processo 65/2009 e aprovada sob número de parecer 09/2010 do Comitê de Ética em Pesquisa do Instituto de Estudos de Saúde Coletiva da Universidade Federal do Rio de Janeiro (IESC/UFRJ).

Os professores de ensino médio que participaram da pesquisa se enquadraram nos seguintes critérios: ser graduado(a) em Educação Física, estar atuante em escolas públicas e/ou privadas e lecionar em pelo menos uma turma do nível médio de ensino. Foi realizado um contato prévio para agendamento do encontro entre pesquisador e pesquisado de modo a garantir espaço e tempo consideráveis e propícios para a investigação.

Utilizou-se como instrumento de coleta de dados uma entrevista semiestruturada cujo roteiro de questões foi previamente validado por professores doutores, especialistas no tema estudado. Tal instrumento pode ser considerado uma das técnicas de coleta de dados mais utilizadas em pesquisas sociais e empíricas, uma vez que pode permitir ao pesquisador compreender de maneira detalhada "as crenças, atitudes, valores e motivações, em relação aos comportamentos da pessoa em contextos sociais específicos" (GASKELL, 2003, p. 65). O número de entrevistas foi estabelecido a partir do ponto de saturação dos dados, isto é, houve a suspensão de inclusão de novos participantes à medida que os dados se tornaram recorrentes (FONTANELLA, RICAS e TURATO, 2008).

Dessa maneira, foram realizadas 21 entrevistas, gravadas em áudio e transcritas na íntegra para análise posterior. O perfil dos pesquisados poderá ser visto de maneira detalhada no Quadro 1.

27 As escolas municipais geralmente não oferecem o Ensino Médio.

28 A Carta de Autorização foi apresentada e aprovada pela Secretaria de Estado de Educação, bem como pelas direções das escolas participantes. 


\begin{tabular}{|c|c|c|c|c|c|c|}
\hline \multirow{2}{*}{ Professor } & \multirow{2}{*}{ Sexo } & \multirow{2}{*}{ Idade } & \multicolumn{2}{|c|}{ Pós-graduação } & \multirow{2}{*}{$\begin{array}{c}\text { Tempo } \\
\text { de do- }\end{array}$} & \multirow{2}{*}{ Escola } \\
\cline { 5 - 6 } & & & $\begin{array}{c}\text { Lato } \\
\text { Sensu }\end{array}$ & $\begin{array}{c}\text { Stricto } \\
\text { Sensu }\end{array}$ & \\
\hline P1 & $\mathrm{M}$ & 46 & $\mathrm{X}$ & & 25 & Estadual \\
\hline P2 & $\mathrm{M}$ & 46 & $\mathrm{X}$ & $\mathrm{X}$ & 8 & Estadual \\
\hline P3 & $\mathrm{M}$ & 42 & $\mathrm{X}$ & & 20 & Federal \\
\hline P4 & $\mathrm{F}$ & 43 & $\mathrm{X}$ & $\mathrm{X}$ & 25 & Federal \\
\hline P5 & $\mathrm{F}$ & 48 & $\mathrm{X}$ & $\mathrm{X}$ & 25 & Federal \\
\hline P6 & $\mathrm{M}$ & 51 & $\mathrm{X}$ & & 26 & Estadual \\
\hline P7 & $\mathrm{F}$ & 29 & & & 3 & Particular \\
\hline P8 & $\mathrm{M}$ & 25 & & & 1 & Particular \\
\hline P9 & $\mathrm{M}$ & 40 & $\mathrm{X}$ & & 25 & Particular \\
\hline P10 & $\mathrm{M}$ & 45 & $\mathrm{X}$ & $\mathrm{X}$ & 23 & Federal \\
\hline P11 & $\mathrm{M}$ & 45 & & $\mathrm{X}$ & 23 & Federal \\
\hline P12 & $\mathrm{F}$ & 35 & $\mathrm{X}$ & & 10 & Estadual \\
\hline P13 & $\mathrm{F}$ & 59 & & & 34 & Particular \\
\hline P14 & $\mathrm{F}$ & 50 & $\mathrm{X}$ & & 28 & Federal \\
\hline P15 & $\mathrm{M}$ & 42 & & & 21 & Estadual \\
\hline P16 & $\mathrm{M}$ & 37 & $\mathrm{X}$ & & 14 & Estadual \\
\hline P17 & $\mathrm{M}$ & 50 & $\mathrm{X}$ & & 29 & Estadual \\
\hline P18 & $\mathrm{M}$ & 49 & $\mathrm{X}$ & & 25 & Particular \\
\hline P19 & $\mathrm{M}$ & 48 & $\mathrm{X}$ & & 21 & Federal \\
\hline P20 & $\mathrm{M}$ & 31 & $\mathrm{X}$ & & 10 & Estadual \\
\hline P21 & $\mathrm{M}$ & 46 & $\mathrm{X}$ & & 23 & Estadual \\
\hline
\end{tabular}

Assim, o grupo de professores entrevistados caracterizou-se por: a) a participação de poucos professores do sexo feminino (6 dentre os 21 entrevistados); b) grande parte dos entrevistados obteve formação em universidades públicas (13 dentre os 21 entrevistados); c) quase todos os professores são pós-graduados (17 dentre os 21 entrevistados); d) poucos entrevistados atuam em escolas particulares (5 dentre os 21 entrevistados), visto que houve mais dificuldade de acesso aos docentes destas escolas e e) média de idade de 43,2 anos e tempo médio de docência de 19,9 anos.

O tratamento dos dados foi realizado a partir da análise de conteúdo proposta por Turato (2003), havendo a elaboração de categorias mediante os critérios de repetição e de relevância nas entrevistas, ou seja, palavras ou ideias que fossem reincidentes (princípio da repetição), bem como as que contribuíssem para os objetivos da pesquisa (princípio da relevância). O processo de categorização se consolidou a partir de inúmeras (re)leituras das entrevistas transcritas a fim de realizar (re)agrupamentos das ideias centrais semelhantes com o auxílio da literatura para definição das categorias ${ }^{29}$.

29 Optou-se por alinhar o nome das categorias às tendências pedagógicas comumente descritas na literatura (DAOLIO, 1995b; DARIDO e RANGEL, 2005). 


\section{Dialogando Com a Empiria}

A historiografia da área de Educação Física e as concepções de corpo historicamente (re)construídas, podem se relacionar ao que foi observado no discurso dos docentes que participaram do estudo, como poderá ser visto nas categorias a seguir.

\section{A Saúde Renovanda e a Influência Médico-Higienista}

A influência médico-higienista foi uma das tendências pedagógicas da Educação Física do fim século XIX e nas primeiras décadas do século XX (SOARES et al., 1992; BRACHT, 1999; CASTELLANI FILHO, 2003; SOARES, 2004). Pode-se afirmar que a visão de corpo atrelada à Educação Física desta época era voltada ao desenvolvimento de homens e mulheres sadios, capazes de construir uma sociedade "livre" de doenças e, consequentemente, preservando a moral coletiva (CASTELLANI FILHO, 2003).

Para Darido e Rangel (2005), a preocupação com o corpo "saudável", tão valorizada atualmente, possui a essência do modelo biológico higienista, porém com algumas características diferentes, isto é, uma "saúde renovada" 30 por incorporar um enfoque mais sociocultural. Assim, as práticas corporais fundamentalmente respaldadas pela perspectiva biológica ainda possuem resquícios da influência médico-higienista (GÓIS JUNIOR e LOVISOLO, 2005).

Nesta perspectiva, é possível observar dentre os entrevistados a necessidade de uma prática pedagógica que resgate alguns dos valores atrelados às tendências supracitadas. Quando os professores se referem ao que deve ser oferecido aos seus alunos nas aulas deste nível de ensino, fica evidenciada a necessidade de um trabalho voltado ao incentivo da prática corporal regular para além da vida escolar visando principalmente à saúde:

Eu acho que a Educação Física, ela pode mostrar a importância da atividade física, não só no que eu falei, mas na questão da manutenção da saúde, de uma vida ativa e a importância de se manter fazendo uma atividade física ao longo da vida e não somente no período escolar. (P2)

[...] que depois ela tenha vontade de continuar a praticar o esporte, que ela dê valor a saúde, que ela se torne um adulto consciente depois da importância da prática da Educação Física, que ela possa depois escolher o que ela gosta de fazer, e nessa idade quem direciona é a escola sim, e o professor de Educação Física. (P4)

Nota-se, nos exemplos, a sugestão que o estudante adquira um estilo de vida ativo e saudável, que deve começar na escola e ser contínua ao longo dos anos, ideia esta que, de acordo com o entrevistado P4, deve ser construída pelo professor de Educação Física do ensino médio por meio de orientações pedagógicas oferecidas em suas aulas. Tal ideia se assemelha à tendência "Saúde Renovada" elucidada por Darido e Rangel (2005). A saúde surge, portanto, como um elemento central na orientação dos alunos do ensino médio, uma

30 Bracht (1999) afirma que tal tendência foi impulsionada pelo número crescente de pesquisas voltado ao campo laboratorial da atividade física, além das recentes discussões do estilo de vida moderno. 
vez que a escola se constituiria como um ambiente propício visando uma educação para a saúde (MAITINO, 2001; NAHAS, 2001).

Sabe-se que uma abordagem voltada para a saúde no ensino médio é amplamente defendida pelos Parâmetros Curriculares Nacionais e as Orientações Curriculares para o ensino médio (BRASIL, 2000 e 2006), documentos que dão respaldo à prática docente em Educação Física. Estas diretrizes consolidadas na área de Educação Física podem justificar a importância comumente dada pelos professores entrevistados ao incentivo à adoção do estilo de vida ativo. Assim, espera-se que os adolescentes incorporariam desde jovem o cuidado com a saúde, em grande medida, associado à prática de atividades físicas.

Segundo a maioria dos discursos dos professores, há uma necessidade latente em conscientizar os adolescentes sobre o valor da regularidade em incorporar boas práticas corporais e hábitos muitas vezes considerados saudáveis:

[...] Ainda agora eu falei pra eles que atividade física na idade deles é uma caderneta de poupança; se eles começarem a se interessar, seja qual atividade eles quiserem: caminhada, dançar, nadar.. eles vão estar plantando para o futuro.. eles precisam, é o que a gente identifica, é que, principalmente os adolescentes, especialmente no ensino médio, é que eles abandonam um pouco a atividade física regular. [...] Eu quero saber se o aluno está com o corpo saudável, se ele consegue tratar da autonomia dele corporal através da alimentação, através de seus cuidados corporais coerentemente [...] (P3)

É importante citar também que os professores utilizam-se do termo "higiene" ligado ao "cuidado com o corpo" para se referirem à sua prática pedagógica com os alunos:

Eu normalmente explico pra eles como eles têm que usar o seu corpo, eles têm que saber usar o corpo. Inclusive até na parte sexual, a parte de higiene. [...] eu não sou professora sexual, né? De assunto sexual, mas a higiene de corpo leva a entender... inclusive estive explicando a eles a diferença do homem para a mulher [...] (P13)

Eu acho que ela deve trabalhar junto com a questão nutricional, eu acho que não dá pra separar a Educação Física da alimentação. Eu acho que as duas coisas têm a ver com a higiene física. (P14)

Segundo Bagrichevsky e Palma (2004), a saúde tem sido entendida e divulgada na Educação Física como consequência da prática regular de atividades físicas em detrimento de aspectos sociais e econômicos que envolvem a vida humana, tornando o sujeito o único responsável pela sua própria saúde. Cooper e Sayd (2006) apontam que os próprios Parâmetros Curriculares Nacionais demonstram que o aluno possui certa responsabilidade pelos seus comportamentos com/para a saúde.

Devide, Oliveira e Ferreira (2005) argumentam que existem questões mais amplas, de origens sociais e econômicas, que influenciam a saúde e que não têm sido tão privilegiadas pelos professores de Educação Física. Tal noção crítica da saúde foi raramente encontrada nos discursos dos professores:

[...] a Educação Física pode simplesmente dar uma idéia de uma atividade física visando à saúde, embora existam textos que questionem isso, porque isso tem muito a ver até com a questão social do individuo, se ele tem condições financeiras [...] (P2) 
Observa-se que independente da concepção de corpo incutida na prática pedagógica docente, o trabalho nas perspectivas de saúde vem a se constituir em um significativo marco no contexto da Educação Física no ensino médio. Miranda, Lara e Rinaldi (2009) também identificaram que professores do ensino médio, de modo geral, entendem ser atividade física e saúde justamente o conhecimento base das aulas de Educação Física.

Ressalte-se, contudo, que preponderou, dentre os entrevistados, determinada noção de saúde em termos de responsabilidade individual, basicamente atrelada à promoção de hábitos ditos saudáveis, como a prática de atividades físicas. Tal noção parece desconsiderar a complexidade dos aspectos que envolvem a saúde, em especial, conjunturais, como os políticos e sócio-econômicos (BAGRICHEVSKY e PALMA, 2004; PALMA et al., 2007).

\section{A Valorização dos Aspectos Técnicos Fpisico-Esportivos: A Influência Competitivista/ Esportista}

Outro ideal de atuação docente que pôde ser detectado nos achados foi vinculado ao trabalho técnico envolvendo o desenvolvimento físico e/ou esportivo. A tendência competitivista e/ou esportivista que permeou principalmente a época do regime militar, durante o século XX (BRACHT, 1999; CASTELLANI FILHO, 2003), exerceu influência importante no campo da Educação Física. Tal período se caracterizou por uma ideia de corpo baseada na capacidade de trabalho e de rendimento individual e coletivo em prol da nação, segundo Daolio (1995b).

A visão de Educação Física e de corpo voltados à técnica e ao desempenho físicoesportivo emergiu significativamente entre os entrevistados:

[...] a partir do momento que você consegue passar um conteúdo para ele, passar uma unidade, dar um voleibol, o corpo ele está inserido dentro de uma preparação física que você queira fazer naquele esporte, que uma criança aguente andar corretamente, correr corretamente. (P4)

Eu explico pra eles o movimento e as partes do corpo que estão realmente sendo usadas porque nós levamos em conta a biomecânica e a biomecânica nada mais é do que o uso do corpo humano, não é isso?! [...] eu oriento para que procure a natação, a hidroginástica, o balé, o basquete mais para os meninos, o futebol também mais para os meninos [...] (P13)

Como pode ser observado nos trechos destacados, há profissionais que utilizam ferramentas de desenvolvimento físico e técnico-esportivas como procedimentos exclusivos da prática pedagógica, valorizando o aluno essencialmente pelo aspecto biológico (DAOLIO, 1995a). De acordo com Daolio e Velozo (2008), hegemonicamente há uma preocupação reducionista, fragmentada, mecanizada e racionalizada com a noção de corpo estritamente no sentido de eficiência técnica para realizar determinada ação. Esta ideia coaduna-se com os PCNs (BRASIL, 2000), quando apontam que o que “[...] predomina no ensino médio é a idéia de que a aula de Educação Física é um espaço para treinamento e aperfeiçoamento das habilidades desportivas." (p. 36)

Por se tratar do último segmento da educação básica, grande parte dos professores privilegia esse momento para se referir especificamente à conscientização de uma prática corporal para que o jovem possa dar continuidade no futuro: 
[...] eu acho que é por aí, o trabalho da escola tem que atender a criança de forma que ela consiga desenvolver fundamentos básicos, habilidades que sejam importantes para que ela tenha condições no futuro de desenvolver uma atividade especifica [...] (P1)

É recorrente na literatura, por exemplo, a hegemonia dos esportes nas aulas de Educação Física em detrimento de reflexões críticas sobre a prática do exercício físico na vida dos alunos (DARIDO, 2001; DARIDO, 2003; DARIDO e RANGEL, 2005). E caberia ao professor fazer a mediação entre o conhecimento técnico-esportivo com o grupo e seus interesses, experiências e demandas determinadas culturalmente (DAOLIO e VELOZO, 2008).

Contudo, os achados da presente pesquisa sugerem que a ideia de prática pedagógica se direciona a uma perspectiva de conscientizar e apresentar as múltiplas possibilidades de exercitar o corpo, principalmente pelo esporte. É possível observar características de um trabalho que tenha como objetivo o desenvolvimento da autonomia do adolescente referente a uma possível prática corporal adotada no momento pós-escolar. A noção principal é estimular o jovem a optar por uma prática corporal quando estiver na fase adulta.

Desse modo, os aspectos técnico-desportivos são trabalhados nas aulas de Educação Física do ensino médio, na realidade estudada, considerando-se questões que ultrapassam os aspectos essencialmente físicos e técnicos. Esta constatação pode indicar um diferencial na atuação destes docentes, quando comparado a pesquisas como a de Beggiato e Silva (2007), que perceberam que as abordagens do professor de Educação Física escolar geralmente estão restritas a conteúdos esportivos.

Pode-se perceber ainda que, de acordo com os entrevistados, a conscientização para o desenvolvimento das capacidades físico-esportivas seria um requisito básico para uma "boa formação corporal" ao longo da vida, fato bastante comum nas discussões acerca desta "formação corporal" voltada ao esporte (KUNZ, 2004; MELO, 2001).

Neste caso, o trabalho com o esporte se coaduna com a tendência anteriormente mencionada, relacionada à saúde, já que a finalidade é gerar autonomia no que se refere à incorporação do hábito da prática regular de atividade física/esporte. Sendo assim, parece ainda estar pautada pelo paradigma da aptidão física relacionada à saúde (DARIDO e RANGEL, 2005).

\section{Tendências Renovadoras ${ }^{31}$ da Educação Física}

A partir da década de 80, com a inserção de referenciais das Ciências Humanas e Sociais nas pesquisas em Educação Física, as discussões a respeito do corpo passaram a adotar o enfoque sociocultural (DAOLIO, 2001). Obviamente, tais referenciais estão ancorados em perspectivas teóricas diferenciadas, principalmente, antropológicas, sociológicas, históricas, pedagógicas e filosóficas. Além disso, mesmo dentro de cada perspectiva,

31 Nesta pesquisa, o termo "renovador" proposto por Soares et al. (1992) se refere àquelas tendências consideradas críticas em relação ao que constituía a prática pedagógica da Educação Física escolar antes da década de 80 . 
reconhece-se haver diferenças conceituais importantes, cujo aprofundamento foge ao escopo deste trabalho. No entanto, é fato que os aspectos socioculturais e epistemológicos definitivamente se incorporam aos debates da área.

Gonçalves (1994), Betti (1995) e Daolio (2003) sugerem que o processo de estruturação do trabalho do professor faça parte do próprio processo de construção identitária da Educação Física. Conforme também elucidado pelos PCNs (BRASIL, 2000), a Educação Física precisa buscar sua identidade como área de estudo para a compreensão do ser humano, enquanto produtor de cultura.

Os professores demonstraram algumas concepções de corpo, no trabalho com seus alunos, que permitem a associação com tendências consideradas renovadoras da área, como a significativa menção sobre a interação, a sociabilidade, o respeito ao grupo e às diferenças.

A sociabilização, o tempo todo (eu estou) preocupada com isso, pra que eles aproveitem essa passagem deles aqui pela escola cada vez mais, aprender a lidar com as diferenças, se sociabilizarem, aprender a respeitar professor, as regras [...] essas discussões que surgem em formar grupos, formar atividades e tudo isso aí a gente tá ajudando a formá-los... a respeitar regras, a se sociabilizar, a aceitar diferenças [...] (P5)

[...] eu venho trabalhando desta forma com uma parcela de disciplina, a parte relacional deles com os outros colegas, através de cooperação, através de desafios... têm vários alunos aqui que chegaram pra mim assim desde pequenos com certas deficiências, e eu acho que quando a gente tem essa visão, eles conseguiram alcançar uma coisa que é muito legal para eles, um espaço dentro da própria turma. (P18)

Dessa forma, parece que o professor do ensino médio se preocupa com a relação entre os jovens, ou seja, a interação social dos "corpos". A ênfase nas relações interpessoais tornase também um elemento importante durante o processo de ensino-aprendizagem nas aulas de Educação Física. Essa perspectiva de corpo parece ser vista como meio de contato direto com o mundo, no qual se apoiaria o trabalho em Educação Física escolar (DAOLIO, 2001).

Por exemplo, paradoxalmente, Sawitzki (2008) detectou o desacordo existente entre os aspectos envolvidos nas tendências renovadoras e a efetiva prática pedagógica de professores de Educação Física escolar. Resende (2001) também já atribuía esta dificuldade à demanda temporal necessária aos docentes para a absorção e aplicação de diferentes estratégias de intervenção pedagógica em relação ao corpo.

Pôde-se perceber ainda a própria expressão "cultura corporal" 32 utilizada de diversas maneiras pelos professores entrevistados, caracterizando a ideia de trabalho voltado às tendências renovadoras da Educação Física:

[...] a gente trabalha mais assim a cultura corporal, né? Então a gente baseia tudo isso na questão do movimento, né? Por que ele faz aquele movimento, em que vai prejudicar ou facilitar a vida dele... é nesse sentido [...] (P6)

32 O termo "cultura corporal" foi cunhado por Soares et al. (1992), com base na pedagogia históricocrítica, derivando a perspectiva crítico-superadora (BRACHT, 1999). Kunz (2004), por sua vez, utiliza o termo "cultura de movimento", partindo de referencial teórico distinto, no que se configuraria uma proposta críticoemancipatória. 
[..] O aluno que vem pra Educação Física, ele traz uma história corporal, ele traz uma história cultural, ele traz uma história política, uma história social, e eu acho que a gente não pode simplesmente negar isso deles. Eu diria que a cultura que eles trazem, que a gente pode chamar de "cultura popular", ela precisa estar dentro da escola e fazer um trabalho com a cultura erudita que a escola produz. [...] E aí nesse sentido, a minha preocupação com o corpo desse aluno é do corpo não como uma máquina, de questão biomecânica, e sim do corpo como uma expressão da sua própria história de vida, da sua cultura e da sua política. (P10)

Sugere-se que o termo "cultura corporal" (SOARES et al., 1992) esteja em relativo destaque no discurso dos professores atuantes no ensino médio da atualidade. Os PCNs (BRASIL, 2000) assinalam que o aluno do ensino médio, após, ao menos, onze anos de escolarização, deve possuir sólidos conhecimentos sobre o que se denomina de "cultura corporal". No entanto, como pode ser visto nos trechos selecionados, há uma polissemia do termo "cultura corporal" para justificar o trabalho pedagógico com/para o corpo durante as aulas.

Cabe frisar que neste texto o termo "cultura corporal" se refere aos conhecimentos historicamente acumulados e socialmente transmitidos que o aluno irá (re)produzir e transformar. Ou seja, os conteúdos da Educação Física Escolar, tais como: jogos, ginásticas, lutas, danças e esportes, são abordados a partir de um enfoque sociocultural, que, do ponto de vista dos PCNs (BRASIL, 2000), deve ser concretizado na medida em que o professor estimula o jovem adolescente a ser crítico e questionador em relação ao corpo.

Logo, aparentemente há uma tentativa do professor de direcionamento da prática pedagógica voltada à cultura corporal, perspectiva essa que se coaduna com os PCNs: "[...] o que se deseja do aluno do ensino médio é uma ampla compreensão e atuação das manifestações da cultura corporal." (BRASIL, 2000, p. 39). No entanto, percebe-se que a conotação atribuída à cultura corporal difere muitas vezes do que se discute na literatura da área.

\section{Considerações Finais}

Ao analisar e discutir as concepções de corpo dos professores de Educação Física atuantes no ensino médio de escolas públicas e privadas, à luz do referencial teórico da historiografia da área, foi possível detectar alguns achados importantes para se pensar a prática pedagógica com os estudantes.

Os resultados indicam que o professor de Educação Física do ensino médio tem apresentado concepções de corpo variadas que coexistem de acordo com os referenciais teóricos que a área de Educação Física vem desenvolvendo ao longo de sua história, influenciando, assim, no processo de ensino e aprendizagem da atualidade. Ainda que a saúde marque significativamente a prática pedagógica da atualidade neste nível de ensino, há considerável preocupação com o desenvolvimento das capacidades físico-esportivas dos alunos, bem como com a abordagem de conteúdos e vivências envolvidos nas tendências consideradas renovadoras da área.

Nesse sentido, a saúde e a abordagem técnico-esportiva poderiam estar sendo trabalhadas em consonância com a noção de responsabilização individual de saúde, descon- 
siderando a importância de se conscientizar os alunos para as questões sociais e políticoeconômicas que a modulam.

Entretanto, parece haver diferentes concepções de corpo observadas no discurso dos professores, uma vez que um mesmo professor pode ter apresentado concepções híbridas de corpo. Observa-se que a representação de prática pedagógica foi elaborada no discurso dos professores a partir de múltiplos referenciais que orientam a área de Educação Física, nem sempre de natureza teórica semelhante. Contudo, tal fato pode indicar um reflexo provavelmente decorrente da área em questão, que é permeada por várias propostas pedagógicas construídas ao longo dos anos. Além disso, os discursos dos professores que possuíam mestrado e/ou doutorado (P2, P4, P5, P10 e P11) aparentemente eram baseados no que tem sido discutido nos últimos anos na literatura em termos conceituais e teóricos, mostrando certa atualização nas informações fornecidas.

Desta maneira, a coexistência de concepções de corpo e de referenciais teóricos diferenciados pode indicar que as diferenças conceituais não são tão nítidas para os professores, embora se note esforço no sentido de se modificar a prática essencialmente técnicoesportiva que normalmente predominava na educação física escolar.

Para futuros estudos, sugere-se como recomendação metodológica ampliar a investigação desta pesquisa por meio da observação participante, a fim de tentar identificar como o "corpo" é, implícita e explicitamente, tratado com os alunos durante o cotidiano das aulas de Educação Física do ensino médio.

\title{
CONCEPTIONS OF BODY AND THE PEDAGOGICAL PRACTICE OF HIGH SCHOOL PHYSICAL EDUCATION TEACHERS
}

\begin{abstract}
The aim of this study was to analyze and to discuss the concepts of body by high school physical education teachers. It was a qualitative research and data were collected using interviews. The subjects were 21 teachers of public and private schools. Data were treated using content analysis. Results indicated that the high school teachers presented different concepts of body which are related to their work context. Health is still the main aim of the pedagogical practice. Nevertheless, there is still a considerable concern about the development of students' physical and sporting skills. Pedagogical contents and experiences related to some innovative trend in the area were also detected. Keywords: Body. Physical Education. Teacher.High School.
\end{abstract}

\section{CONCEPCIONES DEL CUERPO Y PRÁCTICA DE LA ENSEÑANZA DE PROFESORES DE EDUCACIÓN FÍSICA EN LA ESCUELA SECUNDARIA}

Resumen: El propósito de este estudio fue analizar y discutir los conceptos de cuerpo de profesores de educación física que trabajan en escuelas secundarias. La investigación, cualitativa, fue realizada por medio de entrevistas con 21 profesores de escuelas públicas e privadas. Los datos fueron tratados a partir del análisis de contenido. Resultó que el profesor ha presentado diferentes conceptos de cuerpo que coexisten en función de su contexto. Aunque la preocupación por la salud se constituye una marca en la práctica pedagógica de este nivel de educación, hay una considerable preocupación por el desarrollo de habilidades físicas y deportivas de los estudiantes, así como con el enfoque de los contenidos y experiencias presentes en las tendencias de renovación de la educación física.

Palabras clave: Cuerpo. Educación Física. Profesor. Escuelas Secundarias. 


\section{Referências}

ASSIS, S. G. et al. A representação social do ser adolescente: um passo decisivo na promoção da saúde. Ciência \& Saúde Coletiva, Rio de Janeiro, v. 8, n. 3, p. 669-679, 2003.

BAGRICHEVSKY, M.; PALMA, A. Questionamentos e incertezas acerca do estatuto científico da saúde: um debate necessário na Educação Física. Revista da Educação Física/UEM, Maringá, v. 15, n. 2, p. 57-66, Jul./Dez. 2004.

BEGGIATO, C. L.; SILVA, S. A. P. S. Educação Física escolar no ciclo II do ensino fundamental: aspectos valorizados pelos alunos. Motriz, Rio Claro, v. 13, n. 2, supl. 1, p. 29-35, Mai./Ago. 2007.

BETTI, M. A Educação Física não é mais aquela. Motriz, Rio Claro, v. 1, n. 1, p. 81-83, 1995.

BETTI, I. C. R. Educação Física e o ensino médio: analisando um processo de aprendizagem profissional. Motriz, Rio Claro, v. 7, n. 1, p. 23-31, Jan./Jun. 2001.

BRACHT, V. A constituição das teorias pedagógicas da Educação Física. Caderno Cedes, Campinas, v. 19, n. 48, p. 69-88, Ago. 1999.

BRANDL, C. E. H. A nova política para o ensino médio: um estudo da Educação Física a partir das novas diretrizes e dos novos projetos pedagógicos. Revista Brasileira de Ciências do Esporte, Campinas, v. 24, n. 3, p. 71-86, Mai. 2003.

BRASIL, Secretaria de Educação Média e Tecnológica. Parâmetros Curriculares Nacionais: Ensino Médio. Linguagens, códigos e suas tecnologias. Brasília: Ministério da Educação/Secretaria de Educação Média e Tecnológica, 2000.

BRASIL, Secretaria de Educação Básica. Orientações Curriculares para o Ensino Médio: Linguagens, códigos e suas tecnologias. Brasília: Ministério da Educação/Secretaria de Educação Básica, 2006.

CASTELlANi FILHO, L. Educação Física no Brasil: a história que não se conta. 8. ed., Campinas: Papirus, 2003.

CESCHINI, F. L. et al. Prevalência de inatividade física e fatores associados em estudantes do ensino médio de escolas públicas estaduais. Jornal de Pediatria, Rio de Janeiro, v. 85, n. 4, p. 301-306, 2009.

CHICATI, K. C. Motivação nas aulas de Educação Física no ensino médio. Revista da Educação Física/UEM, Maringá, v. 11, n. 1, p. 97-105, 2000.

COOPER, C. L. F.; SAYD, J. D. Concepções de saúde nos parâmetros curriculares nacionais. In: BAGRICHEVSKY, M.; PALMA, A.; ESTEVÃO, A.; DA ROS, M. A. (Orgs). A saúde em debate na Educação Física. v. 2, Blumenau: Nova Letra, 2006, p. 179-202. 
DAOLIO, J. Da cultura do corpo. 6. ed., Campinas: Papirus, 1995a.

DAOLIO, J. Os significados do corpo na cultura e as implicações para a Educação Física. Movimento, Porto Alegre, v. 2, n. 2, p. 24-27, Jun. 1995b.

DAOLIO, J. A antropologia social e a Educação Física: possibilidades de encontro. In: CARVALHO, Y. M.; RUBIO, K. (Orgs.) Educação Física e Ciências Humanas. São Paulo: Hucitec, 2001, p. 27-38.

DAOLIO, J. A ordem e a (des)ordem na Educação Física brasileira. Revista Brasileira de Ciências do Esporte, Campinas, v. 25, n. 1, p. 115-127, Set. 2003.

DAOLIO, J.; VELOZO, E. L. A técnica esportiva como construção cultural: implicações para a pedagogia do esporte. Pensar a Prática, Goiânia, v. 11, n. 1, p. 9-16, Jan./Jul. 2008.

DARIDO, S. C. et al. Educação Física no ensino médio: reflexões e ações. Motriz, Rio Claro, v. 5, n. 2, p. 138-145, Dez. 1999.

DARIDO, S. C. Os conteúdos da Educação Física escolar: influências, tendências, dificuldades e possibilidades. Perspectivas em Educação Física Escolar, Niterói, v. 2, n. 1, (suplemento), p. 5-25, 2001.

DARIDO, S. C. Educação Física na escola: questões e reflexões. Rio de Janeiro: Guanabara Koogan, 2003.

DARIDO, S. C.; RANGEL, I. C. Educação Física na escola: implicações para prática pedagógica. Rio de Janeiro: Guanabara Koogan, 2005.

DEVIDE, F. P.; OLIVEIRA, G. A. S.; FERREIRA, M. S. Ampliando o campo de intervenção da Educação Física escolar a partir da análise da escada da aptidão para toda a vida. Pensar a Prática, Goiânia, v. 8, n. 1, p. 1-19, Jan./Jun. 2005.

FONTANELLA, B. J. B.; RICAS, J.; TURATO, E. R. Amostragem por saturação em pesquisas qualitativas em saúde: contribuições teóricas. Cadernos de Saúde Pública, Rio de Janeiro, v. 24, n. 1, p. 17-27, Jan. 2008.

GASKELL, G. Entrevistas individuais e grupais. In: BAUER, M. W.; GASKEL, G. (ed.). Pesquisa qualitativa com texto, imagem e som: um manual prático. 2. ed., Petrópolis: Vozes, 2003, p. 64-89.

GÓIS JUNIOR, E.; LOVISOLO, H. R. Descontinuidades e continuidades do movimento higienista no Brasil do século XX. Revista Brasileira de Ciências do Esporte, Campinas, v. 25, n. 1, p. 41-54, Set. 2003. 
GÓIS JUNIOR, E.; LOVISOLO, H. R. A Educação Física e concepções higienistas sobre raça: uma reinterpretação histórica da Educação Física brasileira dos anos de 1930. Revista Portuguesa de Ciências do Desporto, Porto, v. 5, n. 3, p. 322-328, Set. 2005.

GONÇALVES, A. S.; AZEVEDO, A. A. O corpo na contemporaneidade: a Educação Física escolar pode ressignificá-lo? Revista da Educação Física/UEM, Maringá, v. 19, n. 1, p. 119130, Jan./Mar. 2008.

GONÇALVES, M. A. S. Sentir, pensar, agir: Corporeidade e educação. Campinas: Papirus, 1994.

KUNZ, E. Transformação didático-pedagógica do esporte. 6 ed, Ijuí: ed. Unijuí, 2004.

LE BRETON, D. Antropologia do corpo e modernidade. Trad. Fábio dos Santos Creder Lopes. Petrópolis, RJ: Vozes, 2011.

LÜDORF, S. M. A. A prática pedagógica do professor de Educação Física e o corpo de seus alunos: um estudo com professores universitários. Pensar a Prática, Goiânia, v. 8, n. 2, p. 243-255, 2005.

MAITINO, E. M. Interfaces da Educação Física escolar com a saúde. Revista Mineira de Educação Física, Viçosa, v. 9, n. 2, p. 96-114, 2001.

MELO, V. A. "Esporte é saúde": desde quando? Revista Brasileira de Ciências do Esporte, Campinas, v. 22, n. 2, p. 55-67, Jan. 2001.

MIRANDA, A. C. M.; LARA, L. M.; RINALDI, I. P. B. A Educação Física no ensino médio: saberes necessários sob a ótica docente. Motriz, Rio Claro, v. 15, n. 3, p. 621-630, Jul./ Set. 2009.

NAHAS, M. V. Atividade física, saúde e qualidade de vida: conceitos e sugestões para um estilo de vida ativo. Londrina: Midiograf, 2001.

PALMA, A. et al. Trabalho e saúde: o caso dos professores de educação física que atuam em academias de ginástica. Cadernos IPUB, Rio de Janeiro, v. 13, p. 11-30, 2007.

RESENDE, H. G. Concepções em torno da relação teoria-prática e suas possíveis implicações no âmbito acadêmico e profissional. Perspectivas em Educação Física Escolar, Niterói, v. 2, n. 1, p. 25-35, 2001.

SAWITZKI, R. L. Esporte escolar: aspectos pedagógicos e de formação humana. Motrivivência, Florianópolis, v. 20, n. 31, p. 132-142, Dez. 2008.

SILVA, M. M. O imaginário social dos acadêmicos de Educação Física da Universidade Federal de Juiz de Fora. Revista da Educação Física/UEM, Maringá, v. 13, n. 1, p. 33-38, 2002 . 
SILVA, K. S.; NAHAS, M. V.; PERES, K. G.; LOPES, A. S. Fatores associados à atividade física, comportamento sedentário e participação na Educação Física em estudantes do ensino médio em Santa Catarina, Brasil. Caderno de Saúde Pública, Rio de Janeiro, v. 25, n. 10, p. 2187-2200, Out. 2009.

SOARES, C. L. et al. Metodologia do ensino de Educação Física. São Paulo: Cortez, 1992.

SOARES, C. L. Educação Física: raízes européias e Brasil. 3. ed., Campinas, SP: Autores Associados, 2004.

TENÓRIO, M. C. M. et al. Atividade física e comportamento sedentário em adolescentes estudantes do ensino médio. Revista Brasileira de Epidemiologia, São Paulo, v. 13, n. 1, p. 105-17, 2010.

THOMAS, J. R.; NELSON, J. K.; SILVERMAN, S. J. Métodos de Pesquisa em atividade física. 5. ed., Porto Alegre: Artmed, 2007.

TURATO, E. R. Tratado da metodologia da pesquisa clínico-qualitativa: construção teórico-epistemológica, discussão comparada e aplicação nas áreas da saúde e humanas. 2 ed. Petrópolis, RJ: Vozes, 2003.

Recebido em: 30/10/2013

Revisado em: 13/02/2014

Aprovado em: 06/05/2014

Endereço para correspondência:

fernanda.ef@ig.com.br

Fernanda Azevedo Gomes da Silva

Universidade Federal do Rio de Janeiro, Centro de Ciências da Saúde, Escola de Educação Física e Desportos.

Av. Pau Brasil, 540 - Laboratório de Biomecânica

Cidade Universitária

21941590 - Rio de Janeiro, RJ - Brasil 